II. RECENZJE I OMÓWIENIA

DOI: $10.17951 /$ et.2015.27.230

Adam Głaz

\title{
UWIĘZIENI W ANGIELSZCZYŹNIE
}

Anna Wierzbicka, Imprisoned in English. The Hazards of English as a Default Language, Oxford-New York: Oxford University Press, 2014, 287 s.

Omawiana monografia to trzecia z kolei tak obszerna publikacja tej autorki poświęcona etnocentrycznym aspektom języka angielskiego (po English: Meaning and Culture (2006) i Experience, Evidence and Sense (2010), omówionej w „Etnolingwistyce" przez Krzysztofa Baja ${ }^{1}$ ), tym razem dotycząca głównie angielszczyzny używanej w humanistyce i naukach społecznych, a więc mających być z założenia obiektywnymi i pozbawionymi konotacji kulturowych. Z charakterystyczną dla siebie analityczną przenikliwością, dbałością o szczegóły, a jednocześnie umiejętnością syntetyzowania, autorka przekonuje, że nic bardziej mylnego - język angielski, mimo statusu języka globalnej wymiany myśli, niesie ze sobą, jak każdy inny język, bagaż typowych dla siebie pojęć, założeń, uprzedzeń i interpretacji zjawisk. Co ważne, pojawiające się w tytule, zaczerpnięte ze świata komputerów, sformułowanie default language 'język domyślny' wskazuje, iż nie chodzi (wyłącznie) o to, „co mają na myśli" rodzimi użytkownicy tego języka, lecz jakie treści uruchamia (najczęściej nieświadomie) każdy użytkownik angielszczyzny poprzez sam fakt posługiwania się nią.

Anna Wierzbicka nie tylko identyfikuje problem, lecz także proponuje jego rozwiązanie. Jest nim oparcie się w publikacjach na - jej zdaniem - prawdziwie uniwersalnych słowach-pojęciach, takich jak ROBIĆ, wIEDZIEĆ, WIDZIEĆ, CZUĆ, MYŚLEĆ, CHCIEĆ, ZŁY, DOBRY itd., a także zbudowanych z nich „,cząsteczek uniwersalnych”, np. MĘŻCZYZNA, KOBIETA, MATKA, OJCIEC, WODA cZy OGIEŃ. W obecnej wersji Naturalnego Metajęzyka Semantycznego tych elementów jest około stu trzydziestu, z czego uniwersalne „atomy" myśli i języka obejmują około stu jednostek. Skonstruowana z nich ,angielszczyzna minimalna” (Minimal English) jest zatem czymś innym niż złożona z około 850 słów „angielszczyzna podstawowa” (Basic English) Charlesa Ogdena ${ }^{2}$, czy też obejmująca ok. 1500 wyrazów „,angielszczyzna globalna”

${ }^{1}$ Anna Wierzbicka, English: Meaning and Culture, New York: Oxford University Press, 2006; tejże: Experience, Evidence and Sense: The Hidden Cultural Legacy of English, New York: Oxford University Press, 2010. Recenzja tej drugiej pozycji: Krzysztof Baj, Kulturowy bagaż języka angielskiego, „Etnolingwistyka” 25 (2013), s. 283-287.

${ }^{2}$ Charles Kay Ogden, Basic English: A General Introduction with Rules and Gram- 
(Globish) Jeana Nerrière'a ${ }^{3}$. Propozycja Wierzbickiej to de facto angielska wersja czegoś, co badaczka nazywa „podstawowym językiem człowieka” (Basic Human), mającym swoje dokładne odpowiedniki w każdym (z założenia) języku świata. Nie chodzi jednak o to, by prace naukowe pisać wyłacznie z wykorzystaniem jednostek uniwersalnych, to bowiem prowadziłoby do absurdu ${ }^{4}$, jednak by definiować przy ich pomocy stosowane tam pojęcia i terminy, a tym samym uniknąć przyznawania statusu pojęć neutralnych i obiektywnych pojęciom anglocentrycznym (Anglo English), wyrażanym przez takie słowa, jak politeness, cooperation, interaction, violence, empathy, emotion, cognition, communication, intentionality, intersubjectivity, a nawet bardziej przyziemne lying, greed, right, wrong, happiness, anger, fear, help, sharing czy brother. Oczywiście język angielski nie jest w tym względzie wyjątkowy i każdy inny powodowałby ten sam efekt - jednak to angielszczyzna zdominowała rozważania naukowe. W tym sensie umieszczony na okładce obraz René Magritte'a Terapeuta, przedstawiający postać ludzką z klatką w miejscu tułowia i głowy, może sugerować nie tylko, że nosimy taką językowo-pojęciową klatkę w sobie, ale wręcz, że nas tak naprawdę nie ma - jest tylko klatka.

Czy zatem rację miał Heidegger, twierdząc, że mówi język, nie my? O ile przypisanie takiej myśli pracom Anny Wierzbickiej jest zbyt ryzykowne, o tyle wydaje się, że brakuje w książce Imprisoned in English wyraźnej kontry, a jeśli jest, to pochodzi ona z przywoływanej przez autorkę na s. 226-227 monografii Jamesa Underhilla Ethnolinguistics and Cultural Concepts ${ }^{5}$. To właśnie Underhill podkreśla rolę podmiotu mówiącego, twierdząc, że jest on w takim samym stopniu efektem działania języka, co jego kreatorem. Odniesienie do Underhilla pozwala także Wierzbickiej na przywołanie lubelskiej szkoły etnolingwistycznej jako przykładu „pokrewnego myślenia” o języku i kulturze (szkoda tylko, że książka Aspects of Cognitive Ethnolinguistics Jerzego Bartmińskiego opatrzona jest błędną datą wydania $^{6}$ ). Chociaż jest to jedyne bezpośrednie nawiązanie do prac lubelskich etnolingwistów, to owo „pokrewne myślenie” można odnaleźć w co najmniej kilku innych miejscach książki. Tak więc, na s. 49 Anna Wierzbicka podkreśla szczególną rolę semantyki leksykalnej jako „przewodnika po ludzkim poznaniu” - w etnolingwistyce lubelskiej leksyka także zajmuje miejsce uprzywilejowane. Na s. 50 pod-

mar, London: Paul Treber, 1930. W wersjach rozszerzonych liczba ta wzrasta do ok. 2000.

${ }^{3}$ Paul Nerrière, Parlez Globish?, Paris: Eyrolles, 2004.

${ }^{4}$ Por. krytykę proponowanych przez Wierzbicką definicji w artykule Romana Kalisza Is it possible to operate with primitives in every explication?, w pracy pod redakcjac Barbary Lewandowskiej-Tomaszczyk Lexical Semantics, Cognition and Philosophy, Łódź: Wydawnictwo UŁ, 1998, s. 55-63. Krótkie omówienie tego tomu: Adam Głaz, Kognitywny i filozoficzny wymiar semantyki leksykalnej, „Etnolingwistyka” 12 (2000), s. 304-309.

${ }^{5}$ James W. Underhill, Ethnolinguistics and Cultural Concepts. Truth, Love, Hate and War, Cambridge: Cambridge University Press, 2012.

${ }^{6}$ Znakomite skądinąd wydawnictwo Oxford University Press nie zawsze dba o wszystkie szczegóły redakcyjne - inny przykład to podwójne datowanie przywoływanego na s. 233 pośmiertnie wydanego zbioru prac Edwarda Sapira Selected Writings in Language, Culture and Personality (1949; data 1924 to prawdopodobnie rok wydania jednej z tych prac, a nie całego tomu). 
kreśla rolę kontekstu w kształtowaniu znaczeń słów, lecz mówi także o sprzężeniu zwrotnym polegającym na kształtowaniu kontekstu przez pojęcia - a zachodzi to dzięki niezmiennemu jądru znaczeniowemu jednostek leksykalnych (według szkoły lubelskiej: znaczeniom prototypowym lub stereotypowym?). I w końcu - by ograniczyć się tylko do trzech przykładów - na s. 240 autorka przywołuje myśl Johna Coetzeego dotyczącą tłumaczenia, które według tego ostatniego polega na przenoszeniu z języka na język stojących za słowami założeń - przypomina to podkreślaną w lubelskiej etnolingwistyce rolę wiązanego ze słowami typu racjonalności.

Jest jednak Anna Wierzbicka badaczką oryginalną, reprezentującą unikalne podejście do języka i niedającą się wpisać w ramy wspólne nawet pokrewnie myślącym etnolingwistom. W swoim mentalistycznym podejściu do semantyki (s. 6-8) zmierza ona, jak wcześniej Bronisław Malinowski, do zrekonstruowania punktu widzenia rodzimego użytkownika języka, inaczej jednak niż Malinowski (ale podobnie jak Franz Boas lub Margaret Mead) kładzie nacisk na intuicję i introspekcję członków badanych społeczności językowych ${ }^{7}$. W kilku punktach wyraźnie różni się też od podejścia reprezentowanego przez szkołę lubelską. Na przykład na s. 47 Wierzbicka sceptycznie odnosi się do tego, co nazywa „semantyką ekstensjonalistyczną" (extensionalist semantics), zwracając uwagę na jałowość poszukiwania nazw rzeczy, ponieważ to nie rzeczy mają nazwy, lecz kategorie (filizanka, ptak). Nie jest jasne, czy jest to krytyka podejścia onomazjologicznego jako takiego, stanowisko szkoły lubelskiej jest jednak wyraźnie odmienne - semazjologia i onomazjologia dopełniają się w możliwie pełnym opisie semantyki słowa. Swoją niechęć do rozważań onomazjologicznych Wierzbicka uzasadnia kilka stron wcześniej, przywołując eksperymenty badaczy z ośrodka w Nijmegen, którzy próbują dotrzeć do sposobu wyróżniania i rozumienia nazw ciała w różnych językach, prosząc badane osoby o ich zaznaczanie i kolorowanie na rysunkach. Nawet jeśli zgodzimy się z rozumowaniem autorki, iż metoda ta jest niewrażliwa na polisemię, nie jest oczywiste, jak uzgodnić jej stanowisko z postulowanym w lubelskiej etnolingwistyce wykorzystywaniem danych przyjęzykowych, czy jest to w ogóle możliwe i - przede wszystkim potrzebne.

Lektura monografii Anny Wierzbickiej nasuwa też szereg innych pytań; wymienię niektóre z nich. Na s. 7 przywoływane jest doświadczenie wyobcowania i zagubienia językowego, znane emigrantom i uchodźcom, tu konkretnie Ewie Hoffman. Odnosząc się do fundamentalnej dla języka i językoznawstwa kwestii relacji między formą i znaczeniem, Wierzbicka przeciwstawia relacji naturalnej (w rodzimym języku) relację arbitralną (w nowo przyswajanym języku obcym). Jest to z pewnością kwestia etykiet terminologicznych, jednak jak pokazuje Hubert Kowalewski ${ }^{8}$, przeciwstawienie naturalności i arbitralności nie jest zasadne, ponieważ

7 Co ciekawe, czasami doszukuje się roli pojedynczego użytkownika, tu konkretnie Marcina Lutra (s. 81), w kształtowaniu niuansów semantycznych. Podobnie rozumuje Przemysław Łozowski w odniesieniu do króla Alfreda Wielkiego (zob. tegoż Language as Symbol of Experience: King Alfred's cunnan, magan and motan in a Panchronic Perspective, Lublin: Wydawnictwo UMCS, 2008, zwłaszcza s. 142-145).

${ }^{8}$ Hubert Kowalewski, Motivating the Symbolic. Towards a Cognitive Theory of the Linguistic Sign, niepublikowana rozprawa doktorska, Lublin, UMCS, 2012. 
arbitralność to szczególny (skrajny) przypadek naturalności, rozumianej jako relacja wyłącznie konwencjonalna.

Na s. 172-173 znajdujemy dyskusję na temat empatii u małp człekokształtnych (ujmowanej przez Wierzbicką w kategoriach jednostek uniwersalnych WIEDZIEĆ CHCIEĆ - CZUĆ oraz ich połączeń) i choć tok rozumowania autorki jest przekonujący, czytelnik zadaje sobie pytanie, czy na podstawie zachowania zwierząt możemy wnioskować o tym, czego one chcą i co czują. Innymi słowy, czy możemy w tym wypadku tak naprawdę wykluczyć działania czysto instynktowne?

Na s. 187 pada między wierszami teza o uniwersalnym charakterze nauk ścisłych - przywoływany jest Galileusz ze swoją wizją matematyki jako języka wszechświata. Tu paradoksalnie wydaje się, iż autorka jest zbyt ostrożna w wyszukiwaniu kulturowo uwarunkowanych aspektów nauki, bo przecież nie ma zgody co do tego, czy matematykę się odkrywa, czy tworzy ${ }^{9}$, a pojęcia w niej stosowane można rozumieć jako pochodne naszego ucieleśnienia, schematów wyobrażeniowych i metaforyzacji ${ }^{10}$. Galileusz jest oczywiście autorytetem, lecz nie mniejszym jest Newton, a co najmniej od czasu odkryć Einsteina wiemy, że fizyka newtonowska ma ograniczone zastosowanie.

Zastanawia traktowanie przez Wierzbicką naszej świadomości śmierci jako wiedzy pewnej i uniwersalnej. Czy wobec ogromnego zróżnicowania wierzeń na temat śmierci, życia pozagrobowego, istnienia i nieśmiertelności duszy, reinkarnacji, kontaktów ze światem duchów itp., możemy uznać fakt, że „wszyscy ludzie umierają" (s. 19) za doświadczeniowy pewnik? Jak sama autorka pisze na następnej stronie, problem nie w tym, iż takich pewników nie ma, ale w tym, że ludzie myślą o nich inaczej - wydaje się, że to uwaga szczególnie trafna właśnie w odniesieniu do śmierci.

Uderza także pominięcie przy (co prawda skrótowym) omawianiu semantyki polskich słów ręka i noga (s. 41-42) wyrażeń takich, jak na ręku (z dzieckiem na ręku) czy też staromodnego całuję nóżki (choć pojawia się całuję raczki). Ich uwzględnienie mogłoby nieco zmienić obraz znaczenia tych jednostek.

Pozostaje wreszcie kwestia tłumaczenia na język angielski terminu językowy obraz świata - na s. 230 użyte jest często spotykane w przekładach polskich prac i niejako intuicyjnie nasuwające się sformułowanie linguistic picture of the world. Podyktowane jest to prawdopodobnie chęcią możliwie dokładnego oddania rosyjskiego terminu jazykovaja kartina mira, w kontekście którego się pojawia, choć nie jest to tłumaczenie, które można przyjąć bezkrytycznie - trafniejsze z wielu względów wydaje się obecne w literaturze anglojęzycznej linguistic worldview ${ }^{11}$.

${ }^{9}$ Krzysztof Wójtowicz, O pojęciu dowodu w matematyce, Toruń: Wydawnictwo Naukowe UMK, 2012.

10 Zob. George Lakoff, Rafael E. Núñez, Where Mathematics Comes From. How the Embodied Mind Brings Mathematics into Being, New York: Basic Books, 2000. Zob. także krytykę ich ujęcia w: Joseph Auslander, Embodied mathematics. „American Scientist” 894 (2001), www.americanscientist.org/bookshelf/pub/embodied-mathematics.

${ }^{11}$ Zob. Adam Głaz, David S. Danaher i Przemysław Lozowski (red.), The Linguistic Worldview. Ethnolinguistics, Cognition, and Culture. London: Versita, 2013, dostęp online: www.degruyter.com/view/product/246955; a zwłaszcza artykuły w tym tomie au- 
Zaznaczmy na koniec, iż powyższe uwagi krytyczne podajemy jedynie z recenzenckiego obowiązku - książka Anny Wierzbickiej jest kolejnym znakomitym wkładem tej autorki nie tylko w rozważania czysto semantyczne, lecz także w szerszą refleksję nad rolą języka i jego wpływem na nasze postrzeganie świata. Jest to wkład szczególnie cenny, ponieważ w sposób uporządkowany obala narosłe przez kilka dekad błędne przekonania co do neutralności angielszczyzny jako języka nauki.

torstwa Elżbiety Tabakowskiej (A linguistic picture, image, or view of "Polish Cognitive Studies", s. 321-338) i Przemysława Łozowskiego (Language vis-à-vis culture in Jerzy Bartmiński's cognitive ethnolinguistics, s. 351-370). 